\title{
ESTUDO DE CASO: CARACTERÍSTICAS DA ABORDAGEM ITERATIVA DE ENSINO EM UM MINICURSO DE C++
}

Gabriel N. S. d'Almeida - gabrielnsdal@gmail.com

Fadoa G. Vieira - fadoaglauss@gmail.com

André R. da Cruz - dacruz@cefetmg.br

Joana A. P. Forte - joanaforte@cefetmg.br

Sandro R. Dias - sandro@decom.cefetmg.br

Centro Federal de Educação Tecnológica de Minas Gerais/Campus II

Avenida Amazonas, 7675, Nova Gameleira

30510-000 - Belo Horizonte - Minas Gerais

Resumo: Este artigo apresenta um estudo de caso de um minicurso de $C++$ em que os organizadores, observando a inadequação do material preparado ao nível do público presente, optaram pela adoção de um método iterativo para realizar quatro aulas de uma hora e meia no mesmo dia. Foram compiladas as falas dos organizadores, e observadas e identificadas as características da metodologia que abordaram. Percebe-se por meio deste artigo a importância da coleta e análise do feedback de participantes; de encontros para decisão e adoção de medidas às necessidades do curso e da construção dinâmica das propostas de aula, que puderam rapidamente solucionar problemas referentes às aulas ministradas anteriormente.

Palavras-chave: $C++$, Curso, Iterativo, Ensino.

\section{INTRODUÇÃO}

O Processo de ensino é formado de vários componentes, dentre eles, os métodos de ensino que, subordinados à aspectos como tempo de aula, público, condições e conteúdo de ensino, visam promover a assimilação de conhecimento da maneira mais adequada possível (LIBÂNEO, 1994). Com experiência, docentes costumam adquirir seus próprios sistemas e métodos, enquanto a reflexão e embasamento filosófico ou científico podem fundamentar toda uma metodologia escolar, específica a determinados públicos ou para determinados conteúdos. Dito isso, na ausência de embasamento a respeito de uma método adequado de ensino para determinado público, seria possível formalizar métodos para desenvoltura de uma metodologia adequada dinamicamente?

Para Gantin (2005), pode-se planejar e sintetizar um plano de ensino eficaz a partir de três pontos chave: um objetivo para aquilo que estudantes devem se tornar, um diagnóstico da distância entre o estudante atual e o ideal, e a proposição de ações concretas que podem ser tomadas para encurtar esta distância, em conformidade ao objetivo e diagnóstico. Um destes elementos, o diagnóstico, só se torna possível com conhecimento da realidade atual, o que impede a criação de métodos eficientes sem a devida experiência. 
Porém, existem metodologias de desenvolvimento ágil que buscam encontrar rapidamente melhores formas de se trabalhar, mesmo com pouco planejamento. A exemplo, temos o framework Scrum, feito sob a perspectiva de que os requisitos de uma tarefa passam por mudanças constantemente, e logo foi feito para ser rapidamente adaptável a mudanças (SCHWABER, SUTHERLAND, 2017). Isso é possível ao trabalhar em um ciclo segmentado entre desenvolvimento (chamado de Sprint), apresentação (chamado de Sprint Review) e avaliação do que foi desenvolvido (chamado de Sprint Retrospective), que pretende sempre melhorar processos de desenvolvimento continuamente. É por meio destas iterações de desenvolvimento que a metodologia Scrum se torna flexível e adaptável, o que pode ser uma ideia promissora para desenvolver uma resposta à pergunta feita anteriormente.

Este artigo analisa o uso de introspecções realizadas entre aulas de um minicurso de C++ realizado pelo COMPET, Programa de Educação Tutorial de Engenharia da Computação do CEFETMG, para elaboração do conteúdo que seria lecionado. Este minicurso ocorreu em Setembro de 2018, na Semana da Ciência e Tecnologia (SEDCITEC) junto à outros minicursos e atividades, no Instituto Federal de São Paulo (IFSP). A SEDCITEC é um evento na comunidade do IFSP que envolve alunos de várias áreas do conhecimento, que podem por meio de oficinas ofertadas serem expostos a temas importantes no mercado de trabalho. Por isso, considerou-se pertinente ao COMPET a realização de atividades de ensino neste evento.

O objetivo deste artigo é delimitar características perceptíveis de uma abordagem iterativa no planejamento de um minicurso de $\mathrm{C}++$ a partir do caso observado, avaliando onde esta poderia ser eficiente ou não.

\subsection{A Linguagem $\mathrm{C}++$}

A linguagem $\mathrm{C}++$ é uma das linguagens de maior importância na história da computação, responsável por inspirar várias outras como Java, Python, Lua, Rust, PHP. C++ foi lançada em 1985, originada da linguagem antecessora C. Criada por Bjarne Stroustrup, C++ objetiva uma evolução imediata da linguagem anterior, dando, segundo o próprio criador, enfoque à aspectos como performance, legibilidade e facilidade de aprendizagem.

$\mathrm{C}++$, ao contrário de $\mathrm{C}$, utiliza o paradigma de Programação Orientada à Objetos, que trata o funcionamento de um sistema como uma coleção de objetos ou atores interagentes (FARINELLI, 2007); ou seja, vê um programa como um conjunto de componentes que interagem entre si. Por meio da Programação Orientada à Objetos busca-se programar apenas pequenos componentes individualmente, reutilizando-os o máximo de vezes possível ao longo do código.

Até 2018, a linguagem era tida como a $6^{\text {a }}$ mais utilizada do mercado e do meio acadêmico (O'GRADY, 2018), sendo uma das mais notáveis linguagens do paradigma de Programação Orientada à Objetos. 


\section{METODOLOGIA}

A concepção da atividade teria sido feita semanas antes, e seu conteúdo fora confeccionado na semana anterior ao início do minicurso. Como não era de responsabilidade do COMPET organizar o ambiente para a realização do curso, este só especificou aos responsáveis o que seria necessário para a realização do evento, e pôde manter o foco na produção do material de ensino.

Todos os alunos do CEFET que foram na viagem para São Paulo foram incumbidos de diversas tarefas no evento realizado no IFSP. O minicurso foi previamente pensado para ser aplicado por 4 (quatro) palestrantes e revezando-se de dois em dois, contudo, por ocorrências imprevistas, 2 (dois) palestrantes membros do COMPET se encarregaram de todas as aulas da atividade. Estes foram amparados por outra dupla de monitores que auxiliaram no acompanhamento dos alunos durante as aulas. Ao longo do dia, foram realizadas 4 (quatro) aulas abordando o mesmo material, com duração de uma hora e meia cada, realizadas às 8:30h, 10:30h, 14:00h e 16:00h. Cada aula teve um total de 20 participantes (lotação total da sala), sendo esses em sua maioria estudantes do IFSP. Para cada estudante, foi designada uma máquina para a realização das atividades.

Os principais tópicos a serem abordados foram:
a) Introdução ao $\mathrm{C}++$
b) Primeiro programa
c) Headers e Includes
d) Namespace
e) Variáveis e Tipos
f) Estrutura de Controle e Repetição
g) Função
h) Classes, Objetos e Métodos
i) Construtores e Destrutores
j) Encapsulamento: Especificadores
k) Herança
1) Reusabilidade
m) Exemplo Prático

No entanto, o planejamento original realizado para o minicurso teria sido deixado de lado logo na primeira das 4 (quatro) aulas que seriam ministradas naquele dia, e aquilo que teria sido colocado no lugar foi uma abordagem iterativa: ministrantes e monitores iriam coletar avaliações por parte dos participantes a respeito da aula que participaram, e com base nestas, decidir quais adaptações iriam adotar no modelo de aula. Após as quatro aulas, o grupo de ministrantes e monitores pôde afirmar ter tido sucesso com o minicurso, tendo resultados positivos em sua atividade.

Muitos materiais utilizados no minicurso, como as avaliações dos participantes, teriam sido perdidos, impossibilitando uma análise adequada da qualidade do minicurso ao longo das quatro aulas. Logo, no intuito de avaliar as características metodológicas do evento sob a perspectiva dos ministrantes e monitores, foi enviado aos organizadores um questionário de 10 (dez) questões abertas a respeito da atividade desenvolvida, preenchido pelos mesmos em abril de 2020. Os itens perguntados foram: 
a) Do que era responsável originalmente durante o evento do minicurso de $\mathrm{C}++$ ? Esta responsabilidade mudou até a conclusão do minicurso?

b) Antes de começar a primeira aula do minicurso, que dificuldades esperava ter de enfrentar?

c) Dificuldades surgiram as quais você não esperava enfrentar? Se sim, quais?

d) Quantas e Quais ideias, adaptações ou compromissos os ministrantes/monitores decidiram tomar ao longo das 4 aulas?

e) Como foi o processo de discutir o que mudar ao longo das quatro aulas?

f) Qual ou quais as consequências que observou ao terem adotado essas medidas? As medidas tiveram o sucesso esperado? Alguma medida teve de ser descartada?

g) Como compararia a primeira aula com a última, tendo em vista aperfeiçoamentos que possam ter ocorrido ao método ou conteúdo lecionado?

h) Em relação à proposta original do minicurso, acha que ele não pôde cumpri-la totalmente? Ou teria ele cumprido ou superado a proposta original?

i) O que mais poderia descrever a respeito da realização deste evento em particular?

As respostas foram colhidas anonimamente, porém, a informação a respeito da função desenvolvida pelo organizador durante a atividade foi recolhida. Sabe-se que os dois palestrantes e um dos monitores responderam ao questionário.

\section{RESULTADOS E DISCUSSÃO}

\subsection{Expectativas para o Evento}

O curso foi pensado para um público já familiar com programação, em particular a programação em C e o paradigma de Programação Orientada a Objetos. Por essa razão, foi confeccionado para abordar as especificidades de $\mathrm{C}++$ comparadas à linguagem $\mathrm{C}$, deixando de lado aquilo que era comum entre as duas linguagens, conforme cita um dos palestrantes: "Espera (sic) encontrar pessoas curiosas, empolgadas e com muitas dúvidas sobre $\mathrm{C}++$ e sua principal diferença em relação ao C"; "Na época, me foi informado que os participantes do curso saberiam orientação a objetos o que não era verdade.”. Existia o receio durante a confecção do curso de que o conteúdo da atividade estivesse abaixo do esperado para alguns participantes, como outro palestrante também diz: "Não sabia se todos os participantes estavam "nivelados'. Tinha medo de ter pegado leve demais no conteúdo"; "Originalmente tinha receio de ter pegado leve no conteúdo mas na prática foi bem o contrário".

Dificuldades no ensino de lógica de programação, no entanto, também eram esperadas, como descreve o monitor: "...Os alunos têm muita dificuldade com a lógica de programação e muitos alunos não têm recursos tecnológicos no dia a dia."

\subsection{Realidades Encontradas}

A necessidade de um conteúdo que fosse mais amplo e didático a respeito das capacidades básicas da linguagem de $\mathrm{C}++$ foi logo observada, com organizadores encontrando um alto índice de alunos dos cursos técnicos que ainda não possuíam conhecimento sobre orientação a objetos. Segundo o monitor entrevistado, para aqueles sem conhecimento prévio de programação, o material do curso abordou tópicos e conceitos complexos demais, o que teria gerado reclamações dos participantes. 
Tal realidade teria sido o principal motivador da desistência do material preparado. $\mathrm{O}$ monitor atribui a situação à uma falta de conhecimento do público alvo, ressaltando que "O grande problema foiter (sic) preparado um conteúdo complexo demais para uma Gama diversificada de alunos.”. Segundo palestrante 1, “... Os participantes eram bem iniciantes então teve-se que 'reinventar' o minicurso todo na hora ...".

\subsection{Medidas Tomadas}

Várias ideias teriam sido exploradas pelos organizadores para melhoria da atividade, porém, seu foco principal eram formas de se ensinar o uso da linguagem $\mathrm{C}++$ sem necessariamente ensinar a programação orientada à objetos, segundo o palestrante 2 .

Os organizadores notaram que o processo envolveu um contato mais pessoal com os participantes, dizendo que uma das medidas buscadas para o sucesso foi "... dando atenção quase que particular aos alunos na medida do possível”, e que "... Todos que solicitaram ajuda foram atendidos pessoalmente ...”. Ainda segundo o monitor, a atenção e ajuda oferecidas aos participantes eram ponderadas de acordo com as dificuldades dos mesmos, e que teriam passado uma parte significativa das aulas os ensinando conceitos básicos.

Segundo um dos palestrantes, a criação do novo conteúdo foi uma ação conjunta, fruto de uma interação eficiente entre os monitores e palestrantes, que se reuniram ao final de cada aula para discutir o que teria dado certo e o que poderia melhorar. Questionários de avaliação foram passados ao final de cada aula aos participantes do minicurso, no intuito de avaliar a satisfação de alunos com a aula. Segundo o monitor entrevistado, foi também levado em conta a "dificuldade dos alunos conforme iam passando exercícios". Os entrevistados descreveram o processo de adoção de mudanças como dinâmico, no qual medidas foram implementadas segundo as necessidades encontradas. Segundo um deles: "No final de cada aula mesmo a gente se reunia e falava o que tinha dado certo e o que melhorar para a próxima.".

A mudança do conteúdo preparado teria sido uma mudança positiva, segundo organizadores. Quando foi pedida uma uma comparação entre a primeira e última aulas, um dos palestrantes notou um possível aumento do engajamento dos alunos: "Foi de um aula que poucos estavam entendendo para uma aula em eles me procuraram para pedir o material de tão interessados em aprender".

\section{CONCLUSÃO}

A partir dos relatos obtidos, é possível observar algumas características importantes do método iterativo adotado: Houve uma maior proximidade com os participantes e uso de observações dos organizadores e comentários a respeito das aulas ministradas como forma de avaliação do conteúdo sendo lecionado. A partir destas avaliações, pôde-se discutir rapidamente se alguma medida deveria ser tomada ou descartada, o que contribuiu com a qualidade das iterações de aula posteriores. Nota-se que isso pode ou não constituir uma vantagem à adoção de um roteiro fixo, dependendo do número de iterações realizadas. Sob um número muito pequeno de iterações, a qualidade média das aulas dadas poderia ter sido insatisfatória.

Nota-se uma similaridade entre as experiências observadas no desenvolver da atividade com aquelas observadas no planejamento de uma aula de matemática (BRUM, 2014). Nele, 
foi-se avaliado o uso de técnicas embasadas na teoria da Aprendizagem Significativa, que pressupõe a aprendizagem como um processo de assimilação de conteúdos novos a partir de sua relação com conhecimentos pré-existentes. Levando em conta estes conceitos, observamos na prática realizada que uma das primeiras atitudes tomadas pelos organizadores foi descartar o foco inicial para as aulas e passar a construir um entendimento da linguagem $\mathrm{C}++$ desde sua base, ou seja, até onde houvesse conhecimento prévio dos participantes por onde ancorar o minicurso. O conteúdo inadequadamente preparado, por sua vez, ancorava-se em conhecimentos inexistentes ao público, impossibilitando assim a assimilação do mesmo.

Em tese, a consolidação destes métodos desenvolvidos iterativamente permitiriam que o conteúdo lecionado por iteração fosse cada vez maior. No entanto, faltam dados para afirmar que este seria o caso. Por hora, pode-se considerar que o uso do processo iterativo pode identificar e tratar da adequação do conteúdo ao público alvo, e é possível especular que poderia trazer mais inovações positivas à estrutura de aula, aumentando sua qualidade.

Não se pode desconsiderar o conhecimento prévio de organizadores em relação à linguagem $\mathrm{C}++$, o que permitiu sanar dúvidas dos participantes e adaptar o conteúdo, identificando quais conceitos melhor se adequam ao público. Tampouco pode-se afirmar que um conteúdo preparado especificamente para os estudantes do minicurso teria menos eficiência que o produto final gerado pelos organizadores. No entanto, o caso atual sugere que o processo de tentativa e erro pode gerar produtos superiores àqueles gerados premeditadamente para uma aula apenas.

\section{REFERÊNCIAS}

BRUM, Wanderley Pivatto; SILVA, Sani de Carvalho Rutz da. Os conhecimentos prévios dos estudantes como ponto referencial para o planejamento de aulas de matemática: Análise de uma atividade para o estudo de geometria esférica. Revista Eletrônica de Educação Matemática, Florianópolis, v. 9, n. 1, p. 43-57, 2014.

FARINELLI, Fernanda. CONCEITOS BÁSICOS DE PROGRAMAÇÃO ORIENTADA A OBJETOS. Instituto Federal Sudeste de Minas Gerais, 2007.

GANDIN, Danilo. Planejamento: Como prática Educativa. $15^{\mathrm{a}}$ Ed, São Paulo: Loyola, 2005.

LAFORE, Robert. Object-oriented programming in $\mathbf{C}++.4^{\mathrm{a}} \mathrm{Ed}$. Indianapolis: Sams Publishing, 2002.

LIBÂNEO, José Carlos. Didática. 1ª Ed, São Paulo: Cortez, 1994.

O'GRADY, Stephen. The RedMonk Programming Language Rankings: January 2018. Disponível em: https://redmonk.com/sogrady/2018/03/07/language-rankings-1-18/. Acesso em 9 de Janeiro de 2019. 
STROUSTRUP, Bjarne. The Essence of C++. Disponível em:

https://www.youtube.com/watch?v=86xWVb4XIyE. Acesso em 25 de Abril de 2020.

SCHWABER, Ken; SUTHERLAND, Jeff. The Scrum Guide. [s.I.]:[s.N.], 2017.

\title{
CASE STUDY: CHARACTERISTICS OF AN ITERATIVE APPROACH FOR TEACHING A C++ SHORT COURSE
}

\begin{abstract}
This article presents a case study of a $C++$ short course, in which the organizers, observing the inadequacy of the current materials to their target audience, opted for the adoption of an iterative method for performing four one hour and a half classes on the same day. Comments from the organizers were compiled and used to observe and identify key characteristics of the approach they had taken. Through this article, it becomes evident the importance of collection and analysis of feedback from participants; of meetings for decision-making of measures relating to the necessities observed; and of the dynamic construction of class proposals, that made possible the quick resolution of problems related to previous classes.
\end{abstract}

Keywords: $C++$, course, iterative, teaching. 